\title{
Trends, Disruption, and our Knowledge-Based Economy
}

Robert Duncan, Vice Chancellor for Research,

University of Missouri

7 he rate of advancement in our markets is accelerating today. Over the last twenty-five years, the primary seat of innovation and discovery has shifted

from industrial laboratories to major, research-intensive universities, and hence social expectations are shifting to universities to lead future advances in technology commercialization that will preserve and extend the United States' international competitiveness. All advances in technology trigger creative disruption of preexisting market structures, and universities are not historically good at managing such disruption. This paper addresses and quantifies these trends through case studies, and then discusses the strategies and structures that we have put in place within the University of Missouri for consideration as a method for management of technical innovation, entrepreneurialism, and the associated creative disruption.

\section{Introduction}

Most scientific and technical innovation today occurs in universities. Twentyfive years ago, $70 \%$ of all R\&D-100 awards were won by industrial laboratories, while today over $70 \%$ of these awards go to universities and public research foundations. Nonetheless, very little direct commercialization is conducted by universities, in favor of technology licensing of university technology to industry. Our future industrial competitiveness will continue to depend more on creating innovative methods of cooperation between universities and industry, and there is opportunity now in innovating new management procedures that permit closer cooperation that bridge across the public and private sectors.

While these changes are themselves very disruptive at many levels, our markets today are becoming more and more accustomed to coping in a continuous state of disruption. In 1920, the average length of time of a company in the S\&P 500 was 65 years, and the S\&P 500 realized only a $1.5 \%$ turn-over rate per year at that time. Today the average S\&P 500 company lasts only on average 20 years, and by 2020 this turnover rate is expected to hit $10 \%$ per year. [Reference: Cleantech Group LLC analysis, from Foster, R. and Kaplan, S., Creative Destruction] So, while disruption of markets is never easily managed, our economy is becoming much more accustomed to rapid change, and it is adapting to this environment successfully. Simply put, business today understands that the best ideas and technology rapidly displace earlier innovations in the markets, and while years ago many companies fought to extend their product life cycles by opposing technological advancement, today there is much more of a philosophy of embracing new ideas, and striving to be on the beneficial side 
of these inevitable disruptions. Similarly, universities that boldly innovate today, and which are open to new and much more aggressive strategies of technology management and industrial relations, will in general win big as well. Today, much more so than ever before, the risk of not taking the risk is actually much greater than the risk itself.

\section{Case Studies}

The fusion of design with technical innovation is essential today. It is not enough to have the best technology, but rather to have the technical designs that are the most readily adapted to the lifestyles and work habits of society. In 1997 Michael Dell said that "If I ran Apple, I would shut it down and give the money back to shareholders". At that time Apple was struggling to survive, with rapidly shrinking demand for its products, which were generally considered to be interchangeable with PC-based computing products like Dell computers. Apple had a market cap of just a few hundred million dollars in 1997, when Dell's market cap exceeded $\$ 20 \mathrm{~B}$.

Then Dell, in my opinion, fell into a common trap: They assumed that the demand for computers was fixed, and that the only way to prosper was to make incremental improvements that only slightly improved their very narrow profit margins. At the same time, in 1997, Apple brought back Steve Jobs as their CEO, and he worked tirelessly to place Apple back on a path of compelling new product development that successfully redefined the market demand for computing and communicating devices. Today Apple's market cap approaches $\$ 600 \mathrm{~B}$, following a $\$ 13 \mathrm{~B}$ profit in the fourth quarter of FY2011 alone, making it one of the very the top profit quarters of any company in history.

Meanwhile, Dell has demonstrated lackluster performance, with a market cap that remains today about where it was in 1997. The important point here is that innovation and customerresponsive design are critically important, and that the opportunity cost of not taking a risk is often far greater than the possible down-side of the risk itself. Universities, which are historically very risk adverse, often operate more like Dell than like Apple, in that they pass huge opportunities in favor of managing the status quo. This is most unfortunate, since usually a university's market position can be preserved and expanded when innovative risks are explored at low cost, if the process is managed properly.

Apple's successes were not derived from putting the current product line in 1997 at risk, but rather were obtained through the careful development of very innovative new products that were only released to the public when their compelling nature was clearly evident. In my opinion, universities, like Apple, are in an excellent position to pursue remarkable new innovations without taking substantial business risk since they are not heavily invested in the current technologies on the market, except in educational technologies.

It is important to realize that modern aviation emerged out of a bicycle shop in Dayton, Ohio, and most of modern physics, including the development of relativity and the seeds of quantum mechanics, emerged from a low-level 
patent clerk in Germany. Too often major universities fall into the trap of thinking that substantial developments must be achieved by following the leadership of the government or other large and more bureaucratic entities. In contrast, history displays time and again that exceptional innovation moves quite disruptively against these well-established trends, without attempting to be disruptive per se. Orville Write said, "If we all worked on the assumption that what is accepted as true is really true, there would be little hope of advance". He said these words at a time when everyone assumed that innovation through carefully controlled experimentation with air foils was futile, and generally a waste of time of 'dreamers' who were incapable more gainful work. In fact, on October 9, 1903, the New York Times reported on the widely accepted opinion of the day when they printed "The flying machine which will really fly might be evolved by the combined and continuous efforts of mathematicians and mechanicians in from one million to ten million years."

Remarkably, on that very same day Orville Wright reported in his diary that "We started assembly today", in reference to the actual flying machine that would successfully sustain the first powered human flight by the end of the calendar year. The point here is that the determined efforts of visionaries have been the only thing that has redefined our thoughts and that have vastly improved our quality of life. So while it is easy for the common wisdom in Universities to think that small visionary efforts cannot create revolutionary advance- ment, in fact it is the only thing in retrospect that has.

While large projects are easily defined today in established efforts, such as genetics and the development of new biotechnologies, universities must remain open in a decentralized way to support innovators who are thought to be pursuing wild, out-of-the box approaches. There is certainly room for both in our major universities, as long as our leadership does not restrict this diversity through an exclusive demand for only centralized, large, and only interdisciplinary collaborative projects that are managed from the top. Large, interdisciplinary projects certainly have their place in the rapid development of new markets around well-defined new science that is based upon much earlier innovations, but the process of discovery itself is almost always decentralized, undervalued, and it appears from unexpected sources.

Many innovators, such as Bednorz and Mueller who shared the Nobel Prize for high-temperature superconductivity, reported after the fact that they had to conduct their research in a clandestine manner to avoid cancellation of their work by the leadership at IBM, Zurich. Too often large-scale research leaders demand a monotonic approach to research project development, and this stifles genuine innovation that often leads to revolutionary discoveries and epic new opportunities. In short, it remains critically important for university leaders to permit innovative faculty members to continue to do research that their peers often consider a clear waste of time. Again, this research environment 
is naturally adaptive to the decentralized structure of universities as long as administrators do not attempt to exert undue centralized control.

Those universities that insist on topdown management in all situations miss the primary advantage of an investigator-led, decentralized research environment, which often proves to be the most profitable aspect of a research university operations in the long run. Of course this does not preclude large, structured research, development, and production operations within universities as well. It just stresses the need for balance, and respect for letting really smart people, typically with tenure, do what they are genuinely inspired to do.

My final case study concerns the development of radio and modern electronics. The early development of the technical innovations by Maxwell, and independently by Hertz, that led to the first transmission of electromagnetic waves in the 1860's remained little more than a novel laboratory curiosity. Then Marconi and Tesla, working separately and often in fierce competition with each other in the late 1890's, developed a string of patents that resulted in early radio devices that realized a small market among typically wealthy customers on ships and in remote, polar regions where no other form of communication was possible. This spurt of innovation was so intense and unusual that it would be much later, in fact in 1946, before the United States Patent Office would overturn Marconi's patents in favor of Tesla's original innovations that led to modern radio.
Still, radio remained an elusive technology, with every radio set being made slowly and at great expense by only highly skilled craftsmen. It wasn't until Edwin Armstrong discovered and patented two important innovations, namely regenerative amplification and heterodyne in the late 1910's that a clear path to the mass production of radios, and later televisions, became clear. These Armstrong patents became the basis that the Radio Corporation of America (RCA) was built upon, and permitted radio to scale to the point where this new modality of broadcasting became available in almost every home within the industrialized world.

The important thing to realize here is that the original discovery of electromagnetic waves, while foundational, was a 'law of nature', and hence not subject to patent protection. The wave of innovations in radio from Marconi and Tesla produced the first patented devices that were based upon this law of nature, but which lacked the detailed systems understanding that would later be provided by Armstrong, which really made this new technology scale. Here, as in many cases, innovations come in waves, with the much larger market penetration come only much later, when the fundamental organizational principles are discovered.

Today universities can take advantage of these natural transitions through interdisciplinary innovation teams that critically evaluate and improve basic discoveries as they emerge, with a focus on how to scale up on the product demand to huge levels. We have such a focused innovation team 
that is active at MU, called the Biodesign Program, which is modeled after a program by the same name at Stanford University. In short, this interdisciplinary design team systematically observes surgical applications of existing operating room technology, and they propose design modifications, some incremental and others fairly revolutionary, that substantially advance the surgical processes in ways that surgeons will rapidly adapt once they are available in the marketplace.

This concept is being broadened from medical instrumentation today to include comparative medicine, and veterinary medical applications. $\mathrm{MU}$ is a Wallace Coulter Foundation Translational Partner, which provides MU with one million dollars a year for five years to develop often revolutionary new biomedical instrumentation. Many programs and faculty member research groups within $\mathrm{MU}$, including the $\mathrm{Bi}$ odesign Program, compete for these funds to develop market viable biomedical devices that are based on MU's intellectual property. Programs such as this and others at MU provide the necessary innovation and resources to build upon initial procedures that may be made to scale to achieve much greater levels of market penetration. The investment in this type of systematic later phase innovations on existing products is a generally low-risk approach, with substantial payoffs, as the Coulter Foundation has demonstrated at fifteen different universities across the United States.

It is interesting to note that the advancement of materials science is often the key to the development of earlier innovations to the point where they scale dramatically, and many properly managed materials programs at universities throughout the world have proven their profound value in this regard. As an example, consider the development of the transistor by Bardeen, Shockley, and Brittan at Bell Laboratories in 1948. This discovery required a wave of new germanium and silicon processing technology before it could truly revolutionize microelectronics to the point where it is today. In the 1950's and into the 1960's transistors were made our of poorly processed and controlled materials, so typically post-production sorting, transistor by transistor, was necessary in order to separate the one in 50 or so devices with exceptionally high performance from the more common ones of adequate performance, and from the majority that simply didn't work. It would take the development of a new process for germanium and silicon purification, called zone refining, at Bell Labs in the 1960s before transistors could be made to work well reliably.

In fact, once the materials purification and refining would permit millions and later billions of transistors to be made to work well within very tight tolerances, the opportunity for a transition to an entirely new level (that of large, integrated microelectronic circuits) would completely revolutionize electronics and issue in the modern microelectronics age, which continues to evolve rapidly according to Moore's Law today. All these are examples of predictable waves of innovation that build upon an initial discovery to create a scalable, new industry of profoundly large propor- 
tions. Universities that prosper will invest intelligently in such teams, such as the Biodesign Program and advanced Materials Programs, to take full advantage of the later waves of innovations that are based predictably on major new discoveries as they emerge.

\section{Acknowledgements}

The author acknowledges many useful discussions with Dr. Paul Dale and his colleagues of the MU Biodesign
Program, Dr. Jake Halliday and his colleagues at the Missouri Innovation Center (MIC) and the MU Biosciences Incubator at Monsanto Place, and with Dr. Tom Skalak, Vice Chancellor for Research at the University of Virginia, and the Principal Investigator within the University of Virginia's very successful Coulter Foundation's Translational Partnership. 